\title{
RESÍDUOS URBANOS: IMPACTOS SOCIOAMBIENTAIS DOS LIXÕES A CÉU ABERTO
}

Amanda de Sousa Barbosa

Graduando em Arquitetura e Urbanismo pelo Centro Universitário Augusto Motta (UNI-

SUAM), RJ, Brasil

amandasousabarbosa@outlook.com.br

Jose Roberto Moreira Ribeiro Gonçalves

Mestre em Engenharia Agrícola e Ambiental pela UFRRJ

Professor do Centro Universitário Augusto Motta (UNISUAM), RJ, Brasil

joserobertoverde@gmail.com

\section{RESUMO}

O presente artigo teve como temática o lixo e os impactos consideráveis causados pelos residuos solidos no ambiente urbano. Registramos que o lixo causa impactos negativos em ambientes urbanos que muitas vezes é causado pela existência de hábitos de disposição final inadequada de resíduos seja por costumes ou até mesmo hábitos culturais da população em diversas cidades do Brasil. Deste modo, o estudo é inspirado pela ideia de prevenção, educação ambiental, reutilização, reciclagem, tratamento e eliminação, ou seja, desenvolvimento sustentavel e de aproveitamente econômico.

Palavras-chave: Impacto ambiental. Lixo. Sustentabilidade

\begin{abstract}
This article has as its theme the trash and the considerable impacts caused by solid waste in the urban environment. We note that the trash causes negative impacts in urban environments that is often caused by the existence of habits of inadequate final disposition of residues either by customs or even cultural habits of the population in several cities of Brazil. In this way, the study is inspired by the idea of prevention, environmental education, reuse, recycling, treatment and elimination, that is, sustainable and economically beneficial development.
\end{abstract}

Keywords: Environmental impact. Garbage. Sustainability 


\section{INTRODUÇÃO}

Atualmente a maior parte das pessoas habita ambientes urbanos. Dados apresentados pelo Instituto Brasileiro de Geografia e Estatística (IBGE) (2004) indicam que no Brasil mais de $80 \%$ das pessoas são moradores urbanos. Considera que a acelerada urbanização e crescimento das cidades, especialmente a partir de meados do século XX promoveram mudanças fisionômicas no Planeta, mais do que qualquer outra atividade humana. (ODUM, 1988).

Segundo o IBGE, cerca de 47.392,2 toneladas de lixo foram despejados em lixões a céu aberto diaramente na última Pesquisa Nacional de Saneamento Básico. Um número que cresce desenfreadamente e que causa cada vez mais impacto negativo na natureza e no ecossistema. (IBGE, 2000).

Os materiais descartados pertos dos cursos d'água, além de transmitirem doenças, são os principais responsáveis pela poluição hídrica. Segundo a Agência Europeia do Ambiente, a cada ano 10 milhões de toneladas de lixo vão parar nos oceanos, no mundo inteiro. Por causa disso, muitos animais marinhos estão morrendo por ingestão de resíduos e asfixia. Niza Silva Jardim e Christopher Wells definem lixo como "[...] os restos das atividades humanas, considerados pelos geradores como inúteis, indesejáveis, ou descartáveis" (JARDIM E WELLS 1995, p. 23).

O presente estudo visa comparar as experiencias dentro e fora do Brasil, uma melhor solução quando se trata de lixões a céu aberto.

\section{ANÁLISE DE EXPERIÊNCIAS BEM SUCEDIDAS, ALEMANHA.}

Líder mundial em tecnologias e políticas de resíduos sólidos - possui os índices de reaproveitamento mais elevados do mundo -, a Alemanha quer alcançar, até o final desta década, a recuperação completa e de alta qualidade dos resíduos sólidos urbanos, zerando a necessidade de envio aos aterros sanitários (hoje, o índice já é inferior a 1\%). Desde junho de 2005, inclusive, a remessa de lixo doméstico sem tratamento ou da indústria em geral para os aterros está proibida.

De acordo com o ambientalista Paulo Affonso Leme Machado:

O termo "resíduo sólido", como entermos no Brasil, significa lixo, refugo e outras descargas de materiais sólidos, incluindo resíduos sólidos e materiais provenientes de operações industriais, comerciais e agrícolas e de atividades da comunidade. (MACHADO, 2007, p. 561). 
Figura 1 - Lixo produzido na Alemanha diariamente.

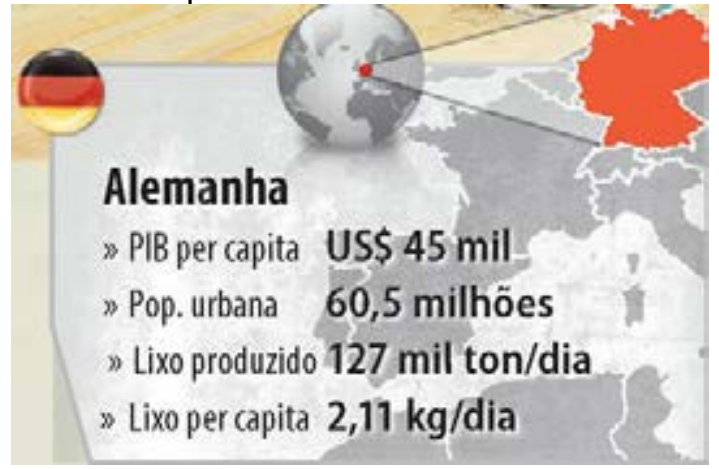

Fonte: (SENADO FEDERAL, 2018).

Entre 2002 e 2010, o total de resíduos urbanos domésticos produzidos pela Alemanha caiu de 52,8 milhões para 49,2 milhões de toneladas. Pode não parecer uma queda grande, mas o importante é o destino que o país tem dado ao lixo. Em 2011, de acordo com o Eurostat, órgão de estatísticas da União Europeia, 63\% de todos os resíduos urbanos foram reciclados na Alemanha (46\% por reciclagem e $17 \%$ por compostagem), contra uma média continental de $25 \%$. Se entre seus vizinhos $38 \%$ do lixo acaba em aterros sanitários, na Alemanha a taxa é virtualmente zero, graças, em grande parte, ao fato de que 8 em cada 10 quilos do lixo não reaproveitado são incinerados, gerando energia.

Segundo Daniel Véras Ribeiro e Márcio Raymundo Morelli:

Existem muitos outros produtos passiveis de reciclagem tais como: plásticos e diversos tipos de polímeros, metais, entulhos oriundos da construção civil, etc. Há em nosso país diversos exemplos de sucesso de municípios e empresas que economizam muito dinheiro com a reciclagem. É necessário agora, que mais empresas e gestores públicos acreditem que é possível encarar os resíduos como um subproduto que, se devidamente trabalhado e com investimentos consistentes, pode se tornar nova fonte de receita e economia (RIBEIRO; MORELLI, 2009, p. 710).

Em 1970, a Alemanha tinha cerca de 50 mil lixões e aterros sanitários. Hoje, são menos de 200. A cadeia produtiva de resíduos emprega mais de 250 mil pessoas. Estima-se que $13 \%$ dos produtos comprados pela indústria alemã sejam feitos a partir de matérias-primas recicladas. Várias universidades oferecem formação em gestão de resíduos, além de cursos técnicos profissionalizantes.

De acordo com Túlio Franco Ribeiro e Samuel do Carmo Lima:

Nas cidades, a coleta seletiva é um instrumento concreto de incentivo a redução, a reutilização e a separação do material para a reciclagem, buscando uma mudança de comportamento, principalmente em relação aos desperdícios inerentes à sociedade de consumo. Dessa forma, compreende-se que é 
preciso minimizar a produção de rejeitos e maximizar a reutilização, além de diminuir os impactos ambientais negativos decorrentes da geração de resíduos sólidos. (RIBEIRO, LIMA, 2000, p. 51).

Figura 2 - Reciclagem de residuos solidos na Alemanha.

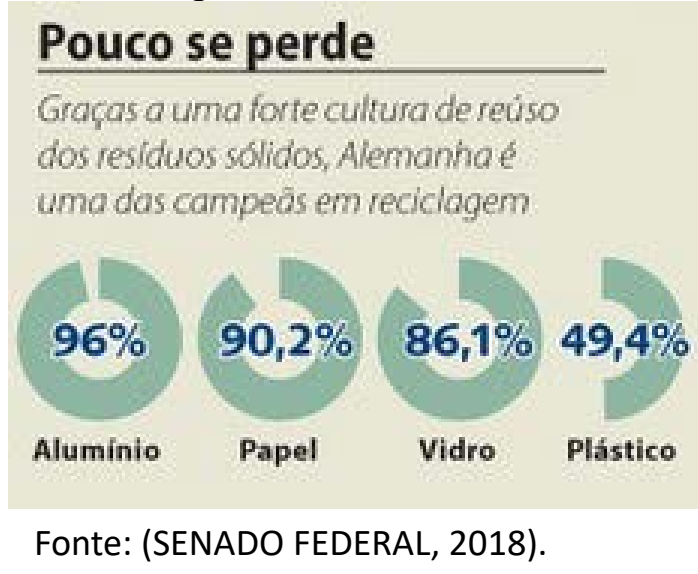

Para se entender os avanços ocorridos na Alemanha, é importante destacar a tradição na cobrança de taxas municipais para a coleta de lixo, desde o século 19. Outro aspecto importante é o uso de vasilhames padronizados e adequados ao acondicionamento do lixo. "Já em 1901, cerca de 75\% dos lares de Berlim dispunham de vasilhames padronizados, e antes de 1851 os proprietários das casas já pagavam taxas pela remoção dos resíduos sólidos domésticos", ensina o professor Emílio Maciel Eigenheer, da Universidade do Estado do Rio de Janeiro (Uerj), no livro A Limpeza Urbana Através dos Tempos. "O lixo, também chamado de rejeito, passa por um processo de exclusão: ele é "posto para fora de casa". Já sob um ponto de vista econômico, resíduo é todo material que é desperdiçado pela sociedade humana. (CALDERONI, 2003).

\subsection{ANÁLISES DE EXPERIÊNCIAS BEM SUCEDIDAS, CURITIBA, BRASIL.}

O aterro sanitário de Fazenda Rio Grande, na Região Metropolitana de Curitiba, é tido como exemplar no modelo brasileiro. A administração é particular, da empresa Estre, que passou a cuidar do lixo produzido em Curitiba e em outros 23 municípios da região em 2010. "Todos têm direito ao meio ambiente ecologicamente equilibrado, bem de uso comum do povo e essencial à sadia qualidade de vida, impondo-se ao poder público e à coletividade o dever de defendê-lo e preservá-lo para os presentes e futuras gerações" (BRASIL, 1988). 
A área, de aproximadamente 260 hectares, tem apenas 62 usados para o descarte. Em média, 350 caminhões descarregam 2,5 mil toneladas de lixo por dia no local, onde são feitos o tratamento e a disposição final de resíduos sólidos de casas, indústrias e comércio. "O primeiro país a dedicar um capitulo inteiro a questão ambiental foi o Brasil. Devido a constituição o sistema de competencia ambiental passou a ter três niveis de governo: federal, estadual e municipal." (Bonilla, 1993).

Figura 3 - Cerca de 350 caminhões por dia descarregam lixo no aterro de Fazenda Rio Grande.

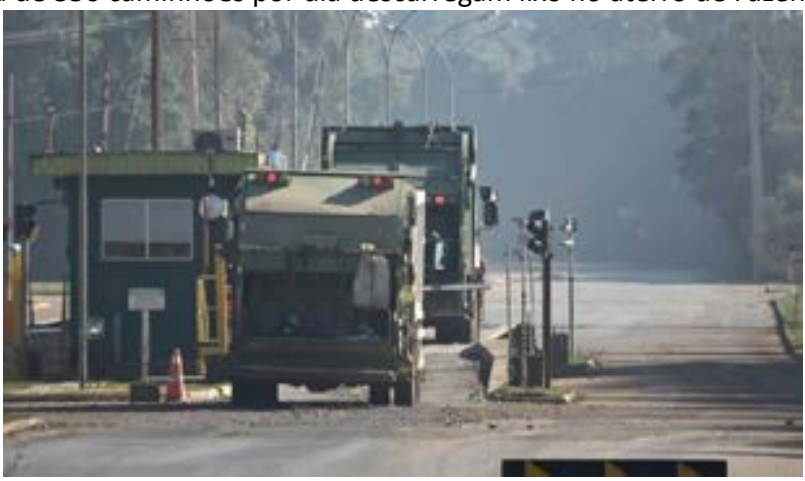

Fonte: (G1, 2018).

“O aterro da Fazenda Rio Grande é bem operado. Tem sistema de tratamento de efluentes, impermeabilização, utiliza biogás, gera energia elétrica, como tem que ser. Todos esses sistemas são necessários para perfeito funcionamento do aterro. Uma boa gestão dá uma vida útil maior ao aterro, o que é sempre bom", comenta a engenheira do IAP Alessandra Mayumi Nakamura.

\section{RISCOS DOS LIXÕES A CÉU ABERTO}

Os lixiviados ou as águas lixiviantes são o resultado da percolação de água, através da massa de resíduos, acompanhada de extração de materiais dissolvidos ou em suspensão. Os lixiviados de formam a partir de água com origem em fontes externas tais como a precipitação, escoamentos superficiais, águas subterrâneas ou águas de nascente. Podem, ainda, ser o resultado da decomposição dos resíduos sólidos depositados. Estes líquidos têm sido identificados como fontes potenciais de poluição do solo, sua gestão inadequada pode causar prejuízos ambientais de grande impacto e difícil reversibilidade, portanto o seu tratamento, condição necessária, reduz sensivelmente os índices de contaminação do solo. "Os processos utilizados para o tratamento dos lixiviados estão bem expandidos no mundo todo, sendo de conhecimento público e tendo como 
caracteristicas as possibilidades de suas rapidas implantações". (Santos, 2008).

Os lixões a céu aberto (aterros comuns) apresentam índices de contaminação humana superiores aos índices de aterros controlados e de aterros sanitários. No caso os índices de aterros controlados são maiores que os índices de aterros sanitários. "Os catadores sabem do risco que estão correndo, mas acabam justificando que o trabalho é sempre em primeiro lugar" (Cavalcante e FRANCO, 2007).

Outro risco extramamente significativo é o vazamento de líquidos contidos no lixos, causando a infiltração e percolação dos líquidos tendo contato com o lençol freático e possível contaminação. No lixão a céu aberto, há bactérias responsáveis pela decomposição da matéria orgânica. Consequentemente, a reação química produz gás metano (CH4), que é responsável pelo aquecimento global. Além disso, quando em contato com o ar, pode provocar incêndios e explosões. A decomposição da matéria orgânica também é responsável por produzir chorume. Esse líquido percolado apresenta a mesma composição dos detritos descartados e pode apresentar concentrações de metais pesados. Dessa forma, no período chuvoso, o chorume pode se infiltrar no solo e contaminar as águas subterrâneas. "Estima-se que a reciclagem realizada de forma adequada seja capaz de evitar a emissão de 18 a 28 milhões de toneladas de dioxido de carbono no Brasil, entre os anos de 2000 a 2007" (GOUVEIA, 2012).

O descarte inadequado de resíduos sólidos pode atrair animais, principalmente ratos portadores da bactéria leptospirose. Por serem eliminadas na urina, essas bactérias se espalham por vários lugares. Em virtude disso, quando há enchentes, pessoas com ferimentos em contato com a água correm o risco de contrair leptospirose. Os principais sintomas são febre, dor de cabeça e dores pelo corpo. Em casos mais graves, os sintomas podem ser meningite, insuficiência renal e o paciente pode ir a óbito.

Segundo Yi- Fu Tuan:

O valor da percepção é fundamental quando se busca solução de determinadas agressões ambientais: "[...] percepção, atitudes e valores - preparam-nos primeiramente, a compreender nós mesmos. Sem a auto-compreensão não podemos esperar por soluções duradouras para os problemas ambientais que, fundamentalmente, são problemas humanos". (TUAN, 1980, p. 1)

Os materiais descartados pertos dos cursos d'água, além de transmitirem doenças, são os principais responsáveis pela poluição hídrica. Segundo a Agência Europeia do Ambiente, a cada ano 10 milhões de toneladas de lixo vão parar nos oceanos, no mundo inteiro. Por causa disso, muitos animais marinhos estão morrendo por ingestão de resíduos e asfixia. "A urbanização das cidades, o crescimento populacional e o consumo 
desenfreado têm contribuído para o aumento de resíduos sólidos urbanos no Brasil. O cuidado com o descarte deste lixo urbano tem crescido com a mesma proporção que a sua produção, tornando fato preocupante as formas incorretas que acontecem na maioria das vezes." (FADINI et al, 2001).

\section{SOLUÇÕES}

O tratamento de lixiviados pode ser realizado de algumas formas, através de tratamento biológico (lodos ativados, lagoas airadas, lagoas de estabilização, lagoas anaeróbias, lagoas de maturação, e reatores anaeróbios de fluxo ascendente), através da 28 de 37 recirculação do lixiviado no meio e por intermédio de tratamento físico-químico. "As formas de tratamento de lixiviados são iguais as técnicas aderidas ao tratamento de esgoto urbano convencional de alguns países desenvolvidos e alguns em desenvolvimento" (CASTILHOS JUNIOR, 2003).

Os lixiviados devem ser drenados e encaminhados para tanques ou lagos de tratamento (o sistema de drenagem funciona à base de bombas de recalque e também por intermédio da gravidade), onde ocorre a fixação de microrganismos degradadores (biomassa ativa) que atuam sobra a matéria orgânica biodegradável presente no lixiviado. A otimização dos processos biológicos inclui o controle do nível de oxigênio consumido, a adição de nutrientes, o controle da concentração de microrganismos, do pH e da temperatura. "O objetivo principal do tratamento biológico é alterar a forma dos elementos orgânicos, não alterando nem destruindo os elementos inorgânicos, apesar de que, estes podem vir a serem removidos" (SANTOS, 2008).

Esta solução necessita que os aterros estejam devidamente impermeabilizados, porém garante que o excesso de líquidos que produzem o lixiviado não vaze devido a transbordamento (geralmente ocorrem com o acumulo de água das chuvas) e entrem em contato com o solo. Apontamos a substituição de lixões a céu aberto (aterros comuns) por aterros sanitários como uma solução que proporcionaria melhorias quanto aos índices de contaminação humana. Contudo esta solução, também poderia ser estendida aos aterros controlados. 29 de 37 A solução apontada não é nova, tanto que ocorreu uma mobilização do poder público neste sentido entre os anos de 1997 e 2008, deste trabalho, onde a Companhia de Tecnologia de Saneamento Ambiental - CETESB mostra o panorama do estado de São Paulo, considerando aterros inadequados, controlados e sanitários. A proliferação de insetos, roedores e demais animais responsáveis por 
contágio acaba sendo muito menor nos aterros sanitários e com isto a proliferação de diversas doenças. A substituição por um aterro sanitário, contudo, não deve ser a única ação a ser executada, é imprescindível a execução de outras ações relacionadas como: a recuperação das áreas dos lixões, após a sua eliminação; a dedetização das antigas áreas de armazenagem, a eliminação dos focos de larvas de insetos através de ações de combate, a implantação de programas de Educação Ambiental, a promoção de políticas e ações sociais voltadas aos catadores de lixo e um a elaboração e implantação de um plano de descontaminação das antigas áreas de armazenagem. "Os resíduos sólidos urbanos de cada município possuem peculiaridade própria de acordo com a população, hábitos, costumes e atividades econômicas desenvolvidas pelos municípios" (JARDIM et al. 1995)

A impermeabilização das trincheiras é uma das soluções mais importantes para evitar a contaminação do lençol freático quando da implantação de um aterro sanitário, e é implementada em duas etapas. A primeira com a impermeabilização do fundo e das laterais do aterro, e a segunda com a impermeabilização final, quando o aterro é fechado devido ao seu esgotamento. Para o emprego desta solução, a escolha da área é fundamental. 30 de 37 Para reduzir os riscos de vazamentos, são utilizadas membranas sintéticas comercializadas em espessuras diferentes, chamadas de Geomembranas. Em geral, aplica-se a geomembrana sobre uma camada de revestimento mineral compactado, o que proporciona dupla segurança, a de não perfuramento da geomembrana por ser colocada sob uma espécie de solo devidamente preparado e o impedimento de contato do revestimento mineral com o lixiviado produzido, o que poderia danificar as condições do revestimento inicial. Uma das facilidades na implantação desta solução é o transporte das geomembranas que são vendidas, geralmente em rolos ou mantas, e sua emenda é realizada por colagem das partes através de maçaricos ou soldadores elétricos. Quanto ao custo, a implantação da geomembrana é mais cara do que a colocação de mantas plásticas, ou do uso simples de revestimentos minerais, porém, as tecnicas comparadas não impossibilitam a contaminação do lençol freático, fazendo com que esta conclusão seja a mais indicada quanto aos custos futuros que podem surgir de uma possível contaminação (CASTILHOS JUNIOR, 2003). 
Figura 4- Partes de um aterro sanitario. CORTE DA SEÇÃO DE UM ATERRO SANITÁRIO

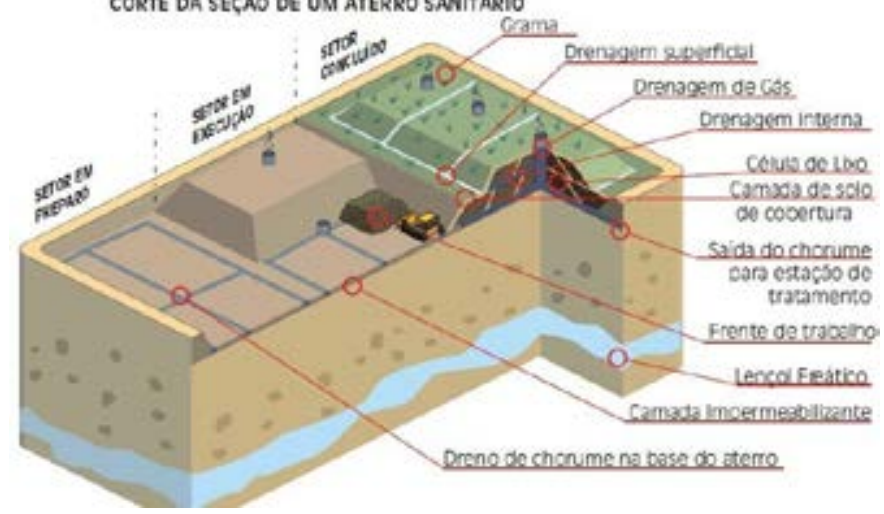

Fonte: (PORTAL RESIDUOS SOLIDOS, 2016).

É preciso empoderar o cidadão, permitindo que a comunidade perceba que faz parte da mudança em busca de meio ambiente equilibrado e sustentável; A sociedade civil precisa estar próxima do governo local, em diálogo com o objetivo do bem comum; A destinação correta do lixo e o fim do desperdício são fruto de trabalho colaborativo; A sustentabilidade e a necessidade de se refletir sobre o lixo produzido devem ser temas trabalhados em sala de aula, fazendo parte da rotina escolar; $O$ consumo de novos bens deve ser, na medida do possível, substituído pela reutilização daquilo que ainda pode ser aproveitado; Os avanços relacionados ao fim do desperdício, às responsabilidades de empresários e à destinação dos produtos descartados precisam estar em legislação do país. "A coleta seletiva do lixo urbano tem se mostrado como um caminho na solução dos problemas ambientais locais, reduzindo o volume de resíduos sólidos deixados nos aterros sanitários ou em lixões a céu aberto, ou seja, exposto no meio ambiente, diminuindo a extração de recursos naturais para fabricação de diversos produtos, além de aumentar a vida útil dos aterros" (COELHO, 2009).

O lixão a céu aberto e o aterro sanitário tem algo em comum. Os materiais destinados à esses dois lugares podem ser comercializados e gerar receita. A reciclagem pode se tornar o sustento para quem não tem o que comer. Além de gerar fonte de renda, diminui a quantidade de lixões e aterros, amenizando os impactos ambientais. "O papel da educação ambiental que propõe mudanças de hábitos para a população é aplicado dentro do contexto da reciclagem, que garante a redução de volume de lixo urbano que é colocado em aterros, aumentando sua vida útil" (NEDER, 1998). 


\section{A LEI 12.305 E AS NOVAS PERSPECTIVAS PARA A GESTÃO DO LIXO URBANO NO BRA- SIL}

Em 02 de agosto de 2010 foi sancionada a lei 12.305 que institui a nova política nacional de resíduos sólidos e, se efetivamente aplicada, deve se afirmar como um divisor de águas na gestão do lixo urbano no país. A nova lei trás definições e reúne um conjunto de princípios, objetivos, instrumentos, metas, diretrizes e ações que devem ser adotadas pelo poder público em parceria com instituições privadas e representativas da sociedade em geral. A política ambiental Brasileira iniciou há quarenta anos como resultado de movimentos populares. "A legislação que essa politica se baseava era formada pela política de águas, florestal e de caça e pesca, mas, no entanto, não havia uma entidade gestora da questão ambiental." (BREDARIOL, 2001).

O capitulo do art. 9o da lei afirma que na nova gestão de resíduos sólidos, deve ser observada a seguinte ordem de prioridade: não geração, redução, reutilização, reciclagem, tratamento dos resíduos sólidos e disposição final ambientalmente adequada dos rejeitos. Percebemos pela redação deste artigo que a não geração vem antes da reutilização na linha de prioridade. Na verdade deveria ser o contrário, uma vez que a reutilização e reciclagem trazem como consequência lógica a redução na geração primária de resíduos. "O poder executivo de um município deve preparar uma instrução que oriente as políticas públicas da implantação da coleta seletiva do lixo urbano e o destino final dos mesmos, para solucionar problemas ambientais do país que prejudiquem a vida" (DIAS, 2003).

A lei prevê, ainda, a criação de um plano nacional de resíduos sólidos, planos estaduais de resíduos sólidos, planos microrregionais e planos de resíduos para regiões metropolitanas, planos intermunicipais de resíduos sólidos, planos municipais de gestão integrada de resíduos sólidos e planos de gerenciamento de resíduos sólidos, estes últimos, destinados aos geradores de resíduos. "As políticas ambientais estão associadas a preservação do meio ambiente e desenvolvimento socia, garantindo a sociedade uma situação sustentavel." (ENG, 2010).

No art. 16 a lei estabelece como condição para os Estados terem acesso aos recursos da União ou controlados por ela, bem como a incentivos e financiamentos das entidades federais de crédito relacionados à gestão de resíduos, a elaboração desse plano estadual de resíduos sólidos. No art. 18 a lei faz a mesma observação em relação aos municípios e ao distrito federal, que terão que elaborar planos municipais de gestão 
integrada contendo, dentre tantas outras coisas: o diagnóstico da situação dos resíduos sólidos gerados no respectivo território, com origem e volume; a caracterização dos resíduos e as formas de destinação e disposição final adotada. A política ambiental ideal é a que incorpora as diversas dimensões da vida humana e da sociedade. "O acolhimento de perspectivas ambiental significa concordar que todos os processos de ajuste setorial e de crescimento estão condicionados pelo envolto biofísico local, nacional e global, com autonomia nacional respeitando a identidade cultural dos povos que se referem." (SOUSA, 2009).

E por fim, e mais importante, o capítulo VI que trata das proibições, veda o lançamento na natureza a céu aberto (exceto os resíduos da mineração) e a queima a céu aberto como destinação ou disposição final para os resíduos sólidos. Na prática, a lei obriga a União, Estados, Distrito Federal e municípios a substituírem as formas tradicionais de gestão do lixo por uma destinação ambientalmente adequada dos rejeitos e, assim, condenam à extinção os famosos lixões a céu aberto, que gradativamente, e vale dizer, lentamente, desaparecerão da realidade de nosso país. "A economia que a humanidade obriga nos dias de hoje com relação aos problemas de ordem ambiental, afeta diretamente a sobrevivencia e o bem estar do planeta com o passar dos tempos simplismente por não buscar soluções que visam a preservação ambiental." (LIMA, 2001).

\section{CONSIDERAÇÕES FINAIS}

A crescente atividade industrial mundial e a ausência de programas eficazes de gestão de resíduos fazem com que cada vez mais resíduos sejam gerados sem que haja uma correta utilização ou depósito destes, o que compromete a qualidade de vida das presentes e futuras gerações.

Como consequência dessa combinação de crescimento populacional nos grandes centros urbanos, aumento desenfreado dos níveis de consumo e a histórica gestão despreocupada dos resíduos sólidos em nosso país, temos hoje instalado um caos ambiental e um grave problema de saúde pública.

O interessante de se observar é que existem soluções economicamente viáveis e ambientalmente adequadas para os problemas gerados pelo lixo, com possibilidade de reaproveitamento energético, reciclagem de materiais, diminuição da produção original e geração de emprego e renda. Dessa forma, um pouco mais de compromisso político e um dos maiores problemas ambientais da atualidade pode se transformar em possibili- 
dades. A lei 12.305 pode ser um bom começo eu uma boa oportunidade para repensarmos nossos propósitos e redefinirmos nossos paradigmas.

Os aterros sanitários possuem características de impermeabilização, de tratamento de lixiviados, de gases e demais elementos críticos desenvolvidas com técnicas bem sucedidas e de domínio público, porém as condições dos catadores de lixo permanecem inalteradas. Sujeitos a riscos constantes representam o reflexo vivo da falta de políticas sociais, educacionais e econômicas relacionadas com a geração de empregos.

Apesar de minimizar os impactos ambientais, os aterros sanitários não são a melhor alternativa de destinação de resíduos sólidos, devido às extensas áreas que ocupam e em função do tempo demandado para que as áreas voltem a ser reutilizáveis (ainda um ponto obscuro nos meios acadêmicos). Na atualidade, existem soluções de menor impacto ambiental, mas ainda com custos muito elevados para implantação, como as Usinas de Incineração à Plasma.

\section{REFERÊNCIAS}

AGÊNCIA EUROPEIA DO AMBIENTE. O lixo nos nossos mares. Disponível em: $<$ https:// www.eea.europa.eu/pt/sinais-da-aea/sinais-2014/em-analise/o-lixo-nos-nossos-mares $>$ Acessado em 01/12/2018.

BONILLA, J.A. Resposta à Crise: Qualidade Total e Autêntica para bens e serviços. São Paulo: Makron Books, 1993.

BRASIL. Constituição da Republica Federativa de 1988. Disponível em: https://www. senado.leg.br/atividade/const/con1988/CON1988 05.10.1988/art 225 .asp.> Acessado em 01/12/2018.

BRASIL. Lei $\mathbf{1 2 . 3 0 5}$ de 02 de agosto de 2010. Institui a Política Nacional de Resíduos sólidos e dá outras providências. Diário Oficial da República Federativa do Brasil. Brasília, 2010.

CASTILHOS JUNIOR, Armando Borges de (coordenador e autor), "Resíduos Sólidos Urbanos: Aterro Sustentável para Municípios de Pequeno Porte" - Florianópolis - SC 2003, Editora Rima Artes e Textos. 
FADINI, P.S.; FADINI, A.A.B. Lixo: desafios e compromissos. Cadernos temáticos de Química Nova na Escola. São Paulo: Sociedade Brasileira de Química. no 1. maio de 2001. p. 9-18.

FIORILLO, Celso Antonio Pacheco. Curso de direito ambiental brasileiro. 8. ed. rev. atual. e ampl. São Paulo, Saraiva, 2007.

G1. Aterros sanitários, aterros controlados e lixões: entenda o destino do lixo no Paraná. Disponível em: <https://g1.globo.com/pr/parana/noticia/aterros-sanitarios-aterros-controlados-e-lixoes-entenda-o-destino-do-lixo-no-parana.ghtml > Acessado em 01/12/2018.

GEEA/UEMA - UNIVERSIDADE ESTADUAL DO MARANHÃO. Lixo e cidadania. Entrevista com Maurílio Rodrigues (coordenador de operações da LIMPEL

GOUVEIA, N. Resíduos sólidos urbanos: impactos socioambientais e perspectiva de manejo sustentavel com inclusão social. Ciênc. Saúde colet, v.17, n.6, p.1503-1510, jun.2012

GOVERNO DO BRASIL. Países destacam experiências bem-sucedidas de descarte correto de lixo. Disponível em: <http://www.brasil.gov.br/noticias/meio-ambiente/2018/06/paises-destacam-experiencias-bem-sucedidas-de-descarte-correto-de-lixo. Acessado em 01/12/2018.

INSTITUTO BRASILEIRO DE GEOGRAFIA E ESTATÍSTICA - IBGE. Censo 2000. Indicadores de desenvolvimento sustentável: disposição de resíduos sólidos urbanos. Disponível em: <<http:// www.lbge.gov.br >>. Acessado em 01/12/2018.

INSTITUTO BRASILEIRO DE GEOGRAFIA E ESTATISTICAS. Quantidade de lixo coletado. Disponível em: https://sidra.ibge.gov.br/tabela/2332\#resultado > Acessado em 01/12/2018. 
IPEA INSTITUTO DE PESQUISA ECONÔMICA APLICADA. Brasil perde 8 bilhões por

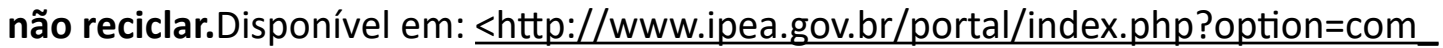
content\&id=1170>Acessado em 01/12/2018.

JARDIM, N. S.; WELLS, C. (Org.). Lixo Municipal: Manual de Gerenciamento integrado. São Paulo: IPT: CEMPRE, 1995.

LIMA, Jose Dantas de, "Gestão de Resíduos Sólidos Urbanos no Brasil”, Paraíba, 2001, Editora João Pessoa.

MACHADO, Paulo Affonso Leme. Direito Ambiental Brasileiro. 15. ed. rev. atual. e ampl. São Paulo: Malheiros, 2007.

MACHADO, Paulo Affonso Leme. Direito Ambiental Brasileiro. 15. ed. rev. atual. e ampl. São Paulo: Malheiros, 2007.

MAGRO DIONYSIO, Luis Gustavo; BARBOSA DIONYSIO, Renata. Lixo urbano: descarte e reciclagem de materiais. 2008. Disponível em: $<<$ http://web.ccead.puc-rio.br/condigital/mvsl/Sala\%20de\%20Leitura/conteudos/SL_lixo_urbano.pdf $\gg$. Acessado em 01/12/2018.

MILARÉ, Édis. Direito do ambiente: agestão ambiental em foco. Doutrina, jurisprudência, glossário. 5. Ed. ref., atual. e ampl. - São Paulo: Editora Revista dos Tribunais, 2007.

MUCELIN, Carlos Alberto; BELLINI, Marta. Lixo e impactos ambientais perceptíveis no ecossistema urbano. Sociedade \& Natureza. jun. 2008. Uberlândia, 2008. Disponível em: <<www.sociedadenatureza.ig.ufu.br/include/getdoc.php?id=632 >>. Acesso em: 21 out. 2010.

PORTAL RESIDUOS SOLIDOS. O impacto causado pelos lixões à céu aberto. Disponível em: https://portalresiduossolidos.com/o-impacto-dos-lixoes/ Acessado em 01/12/2018.

PORTAL RESÍDUOS SÓLIDOS. Lixão (Vazadouro) a céu aberto. Disponível em: < $\underline{\text { https:// }}$ 
portalresiduossolidos.com/lixao-vazadouro-a-ceu-aberto/ > Acessado em 01/12/2018.

RIBEIRO, Daniel Verás; MORELLI, Márcio Raymundo. Resíduos sólidos: problema ou oportunidade? Rio de Janeiro: Interciência, 2009.

RIBEIRO T. F., LIMA S. C. Coleta seletiva de lixo domiciliar - estudos de casos. Caminhos de Geografia, vol.1, n.2, p. 50-69, dez. 2000.

SANTOS, Inês Margarida de Barros Tavares dos, "Diagnóstico e Avaliação da Gestão de Lixiviados Produzidos em Aterros Sanitários de Resíduos Urbanos - Caso de Estudo - Sistemas Intermunicipais", Lisboa, 2008, Tese de Mestrado submetida à Faculdade de Ciências e Tecnologia da Universidade Nova de Lisboa. Disponível em: <http:// www. dspace.fct.unl.pt/bitstream/10362/1441/1/TSantos 2008.pdf> Acessado em 01/12/2018.

SENADO FEDERAL. Como alguns países tratam seus resíduos. Disponível em: $<\underline{\text { https:// }}$ www12.senado.leg.br/emdiscussao/edicoes/residuos-solidos/mundo-rumo-a-4-bihoes-de-toneladas-por-ano/como-alguns-paises-tratam-seus-residuos $>$ Acessado em 01/12/2018. 